\title{
Promotion of photodynamic therapy-induced apoptosis by stress kinases
}

\author{
Liang-yan Xue ${ }^{1}$, Jin $\mathrm{He}^{1}$ and Nancy L. Oleinick ${ }^{\star, 1}$ \\ ${ }^{1}$ Department of Radiation Oncology, Case Western Reserve University School \\ of Medicine, Cleveland, Ohio, OH 44106-4942, USA \\ * corresponding author: Department of Radiation Oncology, School of Medicine \\ (BRB-324), Case Western Reserve University, 10900 Euclid Avenue, \\ Cleveland, Ohio, OH 44106-4942, USA. tel: 216-368-1117; \\ fax: 216-368-1142; e-mail: nlo@po.cwru.edu
}

Received 22.03.99; revised 24.06.99, accepted 28.06.99

Edited by $\mathrm{C}$. Thiele

\begin{abstract}
Photodynamic therapy (PDT), a cancer treatment that employs a photosensitizer and visible light, induces apoptosis in murine LY-R leukemic lymphoblasts and in $\mathrm{CHO}$ cells, but the rate and extent of apoptosis are much greater in LY-R cells. Three MAPK family members, ERK1/ERK2, SAPK/JNK, and p38/HOG, are important intermediates in signal transduction pathways. To ascertain whether activation of one or more MAPKs could mediate PDT-induced apoptosis, Western blot analysis has been performed on the proteins of $\mathrm{LY}-\mathrm{R}$ and $\mathrm{CHO}$ cells at various times following lethal $(90-99 \%$ cell kill) doses of PDT photosensitized by the phthalocyanine Pc 4. The blots were probed with antibodies to each of the proteins as well as antibodies specific for the activated (phosphorylated) forms of each kinase. Of the three MAPK types, only the p46 and p54 SAPK/JNKs were found to be activated by PDT in LY-R cells, with a maximum $\sim$ threefold increase in the content of the phosphorylated forms reached in 30-60 min. An even larger relative activation was observed in $\mathrm{CHO}$ cells. PDT did not affect ERK and p38/HOG activation in LY-R cells. In the case of CHO cells, however, ERK2 was slightly activated at 5 min postPDT, then declined, and P38/HOG was strongly activated from 5 to 60 min post-PDT. A specific inhibitor (PD98059) of MEK1, the kinase that activates ERK, had little or no effect on PDTinduced apoptosis in either LY-R or $\mathrm{CHO}$ cells. In contrast, a specific inhibitor of P38/HOG (SB202190) blocked PDTinduced apoptosis in LY-R cells with a lesser effect in CHO cells. The results suggest that both the SAPK and p38/HOG cascades can be stimulated by PDT and that the latter participates in both rapid and slow PDT-induced apoptosis. Furthermore, the high level of constitutively active P38/HOG in LY-R cells may poise those cells for rapid activation of apoptosis following PDT.
\end{abstract}

Keywords: photodynamic treatment; phthalocyanine; Pc 4; apoptosis; mitogen-activated protein kinases; PD98059; SB202190
Abbreviations: $\mathrm{CHO}$, Chinese hamster ovary; ECL, Enhanced chemiluminescence; ERK, extracellular regulated kinase; FITC, fluorescein isothiocyanate; LY-R, L5178Y-R; MAPK, mitogenactivated protein kinase; p38/HOG, p38/hyperosmotic glucoseregulated kinase; PDT, Photodynamic therapy; PI, propidium iodide; PMA, phorbol myristate acetate; SAPK/JNK, stressactivated protein kinase/c-Jun $\mathrm{N}$-terminal kinase; SDS, sodium dodecyl sulfate

\section{Introduction}

Photodynamic therapy (PDT) employs a tumor-localizing photosensitizer and visible light to produce singlet oxygen and other reactive oxygen species, ${ }^{1-3}$ leading to lipid peroxidation and membrane damage and finally cell death and tumor ablation. PDT induces apoptosis in mouse L5178Y-R (LY-R) lymphoma cells ${ }^{4}$ as well as a variety of other cell types. ${ }^{5-7}$ In our previous investigation into the mechanism of PDT-induced apoptosis in LY-R cells, we found that PDT stimulates a series of membrane-associated reactions, including activation of phospholipases $\mathrm{C}$ and $\mathrm{A}_{2}{ }^{8}$ the release of intracellular $\mathrm{Ca}^{2+}, 8$ and the increased synthesis of the lipid second messenger ceramide. ${ }^{9}$

Apoptosis is a prominent mechanism of cell death following the exposure of many cell types to toxic agents. ${ }^{10}$ In order to elucidate the signaling pathways responsible for the regulation of apoptosis, the roles of the members of the MAPK family have been widely studied, because these kinases are important intermediates that convert extracellular signals into intracellular reponses. Xia et all first reported the opposing effects of the MAPK family members, ERK1 and ERK2 vs SAPK/JNK and p38/HOG, on apoptosis. They found that SAPK and p38 were activated and ERKs were inhibited in PC-12 pheochromocytoma cells when apoptosis was induced by the withdrawal of nerve growth factor. The opposing effects of SAPK and ERK on apoptosis induced by other stimuli, including ceramide, adriamycin, ionomycin, nitric oxide and Fas, as well as oxidative stresses, e.g., tumor necrosis factor, X-rays, $\mathrm{H}_{2} \mathrm{O}_{2}$, and UVC, have also been reported. ${ }^{12-16}$ Recently, the role of p38 in the control of apoptosis has been studied using specific inhibitors of this kinase. Frasch et al ${ }^{17}$ reported that stresses, such as UV, hyperosmolarity, or sphingosine, activated p38 and that the resultant apoptosis could be inhibited by the p38 inhibitor SK\&F86002. Two related pyridinyl imidazoles, SB203580 and SB202190, inhibit both the $\alpha$ and $\beta$ isoforms of p38. ${ }^{18-20}$ SB203580 has been shown to inhibit BCR ( $B$ cell receptor)-induced apoptosis in human $B$ cell lines ${ }^{21}$ and apoptosis of neural cells induced by either trophic factor withdrawal or glutamate treatment and sodium salicylate-induced apoptosis in fibroblasts. ${ }^{22-24}$ 
In spite of expanded interest in studying the importance of the MAPK family on apoptosis, little is known concerning the potential involvement of these kinases in apoptosis induced by PDT. The activation of SAPK and $\mathrm{p38} / \mathrm{HOG}$ by PDT has been reported for both murine ${ }^{25}$ and human ${ }^{26}$ keratinocytes and other human cells. ${ }^{26}$ However, neither group presented evidence concerning the level of cell death achieved by the PDT doses studied, whether the cells died by apoptosis or necrosis, or whether the stimulated pathways mediated cell death or were epiphenomena.

There is now strong evidence that PDT with photosensitizers that localize to mitochondria, such as $\mathrm{Pc} 4,{ }^{27}$ promotes the prompt efflux of cytochrome $\mathrm{c}$ that initiates the caspase-9 and -3-dependent pathway of apoptosis. ${ }^{28-30}$ However, it is clear that the rate and extent of apoptosis can be modulated by certain signaling pathways. For example, we recently showed that the non-receptor tyrosine kinase Etk provides an anti-apoptotic signal in prostate cancer cells. ${ }^{31}$ In order to determine whether the MAPKs are involved in the regulation of PDT-induced apoptosis, we have studied two cell lines: LY-R cells, that undergo rapid induction of apoptosis beginning as early as 15 min post$\mathrm{PDT}$, and $\mathrm{CHO}$ cells, that initiate apoptosis more slowly. The level of phosphorylation of ERK1/ERK2, SAPK/JNK, and p38/HOG was examined in untreated and PDT-treated cells.
The relationship between the activation of these MAPK family members and apoptosis was investigated.

\section{Results}

Photodynamic therapy (PDT) is a potent inducer of apoptosis in many types of cells. ${ }^{7}$ In our previous studies, it was found that PDT with the phthalocyanine photosensitizer Pc 4 induces apoptosis in both LY-R and $\mathrm{CHO}$ cells, as measured by oligonucleosomal DNA fragmentation, morphological changes, and flow cytometric analysis. ${ }^{4,8,32}$ However, the two cell lines differed in both the rate and extent of apoptosis in response to PDT. Apoptosis occurred rapidly in LY-R cells, beginning as early as 10-20 min post-PDT ${ }^{8}$ and ultimately involving all cells in the culture. The response was slower and less extensive in $\mathrm{CHO}$ cells. ${ }^{32}$

In order to confirm the time course and extent of apoptosis in PDT-treated LY-R and CHO cells, the TUNEL assay and flow cytometry were employed (Figure 1). Apoptotic cells were labeled by addition of fluorescein isothiocyanate-dUTP (FITC-dUTP) to DNA ends using terminal deoxynucleotidyl transferase, and DNA was further labeled with the intercalating dye propidium iodide (PI). The apoptotic cells appear as a second population with high fluorescein fluorescence. Figure 1 displays
A:LY-R

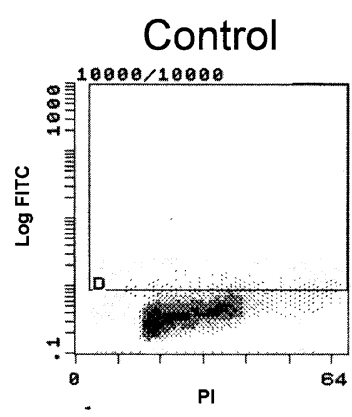

2.4

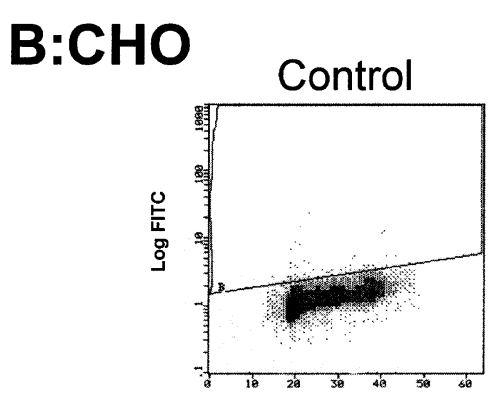

2.5

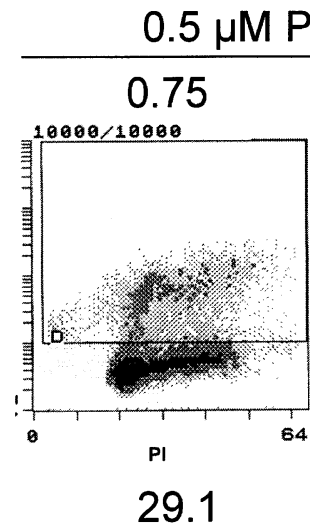

29.1

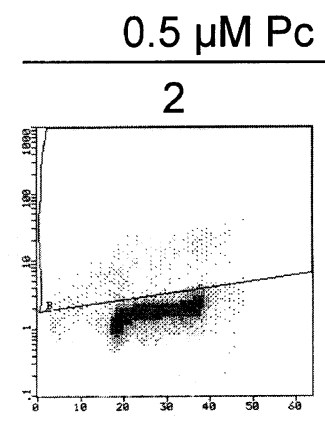

PI

6.0

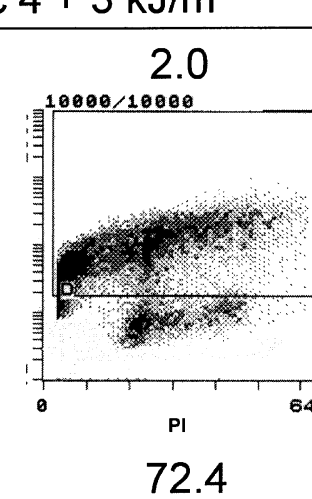

72.4 h post-PDT

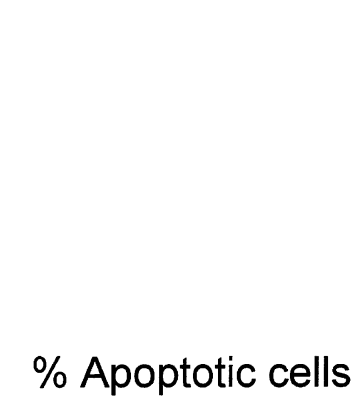

$4+10 \mathrm{~kJ} / \mathrm{m}^{2}$

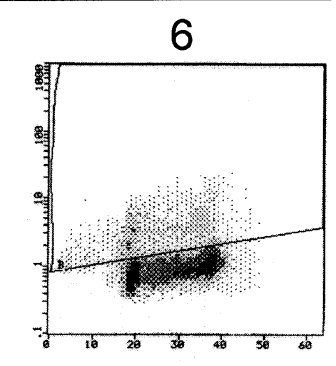

PI

21.3

h post-PDT

\section{$\%$ Apoptotic cells}

Figure 1 PDT-induced apoptosis in LY-R and $\mathrm{CHO}$ cells as measured by flow cytometry. For PDT, cells were incubated with $0.5 \mu \mathrm{M} P c 4$, then irradiated with $3 \mathrm{~kJ} /$ $\mathrm{m}^{2}$ and $10 \mathrm{~kJ} / \mathrm{m}^{2}$ for LY-R and CHO cells, respectively. Controls were exposed to Pc 4 but not light. At the indicated post-PDT time, cells were stained with FITCdUTP and PI and analyzed by flow cytometry, as described in Materials and Methods. The upper and lower series of histograms are for LY-R cells (A) and CHO cells (B). The number under each histogram is the \% apoptotic cells calculated as the percentage of cells with high FITC staining (box in each histogram) 
representative flow cytometry histograms and the estimated percentage of apoptotic cells in LY-R (Figure 1A) and $\mathrm{CHO}$ cells (Figure 1B) which were either untreated or treated with isotoxic ( LD 99) PDT doses. As shown in Figure 1A, 29\% of the LY-R cells were undergoing apoptosis by $45 \mathrm{~min}$ after PDT, and the apoptotic cell population reached $72 \%$ by $2 \mathrm{~h}$ post-PDT. In contrast, only $6 \%$ of the $\mathrm{CHO}$ cells were observed to be in apoptosis $2 \mathrm{~h}$ post-PDT, and the content of apoptotic cells increased to $21 \%$ by $6 \mathrm{~h}$ postPDT (Figure 1B). These time courses are in agreement with previous more extensive analyses..$^{9,32,33}$ The results confirmed that apoptosis induced by PDT in $\mathrm{CHO}$ cells was slower and less extensive than in LY-R cells.

We have reported ${ }^{8,9,33}$ that PDT stimulates a series of membrane-associated signal transduction reactions. We have also found that PDT causes a rapid stimulation of the tyrosine phosphorylation of two major proteins of $\mathrm{Mr}$ $\sim 80000$ and $\sim 55000$ in LY-R cells; the response was PDT dose-dependent and occurred as early as $20 \mathrm{~s}$ after the initiation of light exposure of Pc 4-preloaded cells. ${ }^{33}$ By immunoprecipitation and Western blot analysis, one of the $\mathrm{Mr} \sim 80000$ phosphorylated proteins has been identified as HS1, a substrate of non-receptor-type src protein tyrosine kinases. To further elucidate the signaling pathways responsible for the regulation of PDT-induced apoptosis, the ability of PDT to activate three major MAPK sub-types (ERK, SAPK and p38/HOG) was investigated. Figure 2 presents Western blot analyses of proteins from control and PDT-treated LY-R and $\mathrm{CHO}$ cells using a highly sensitive phospho-specific anti-p44/42 ERK antibody which recognizes only the phosphorylated forms of these proteins. As a positive control, some cultures were incubated with $100 \mathrm{nM}$ phorbol myristate acetate (PMA) for $20 \mathrm{~min}$. As shown in the top panels of Figure 2A,B, ERK2 (42 kDa) was found to be partially activated in untreated cells of both LY-R and $\mathrm{CHO}$ cultures, and PMA produced a strong activation of ERK2 and a lesser response of ERK1 (44 kDa). In the case of LY-R cells, doses of PDT that result in 90 or $99 \%$ loss of clonogenicity $(0.5 \mu \mathrm{M} \mathrm{Pc} 4$ and $2.1 \mathrm{~kJ} / \mathrm{m}^{2}$ or $3 \mathrm{~kJ} / \mathrm{m}^{2}$, respectively) produced no detectable change in the level of phosphorylation of either ERK1 or ERK2 at any time up to $1 \mathrm{~h}$ post-PDT. In contrast, equitoxic doses of PDT to $\mathrm{CHO}$ cells resulted in a slight elevation of the level of phospho-ERK2 at $5 \mathrm{~min}$ post-PDT (top and bottom panels of Figure 2B).

The bottom panel of Figure $2 \mathrm{~A}$ and the middle panel of Figure 2B show Western blot results using the control antiERK antibody to correct for unequal protein loading. As shown by the densities of the ERK1 bands, there was approximately equal loading among these samples. However, the densities of the ERK2 bands in samples from PMA-treated cells and from $\mathrm{CHO}$ cells 5 min after PDT were weaker than in other samples. One possible explanation is that the control anti-ERK antibody is less sensitive to phosphorylated ERK2 than to non-phosphorylated ERK2. Based on the above observations and the results of staining gels with Coomassie blue to confirm sample loading (data not shown), the ERK1 band, rather than ERK2, was used as a standard to calculate the relative amount of phosphorylated ERK2 in Figure 2B. The
A

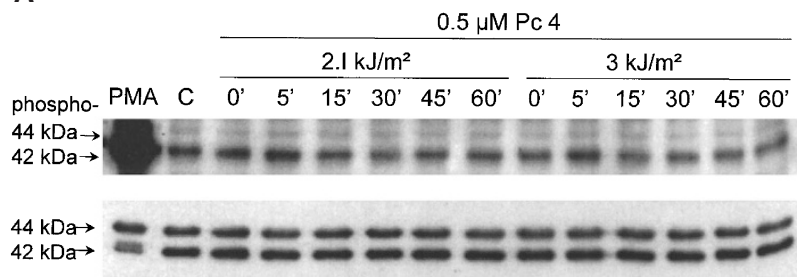

B

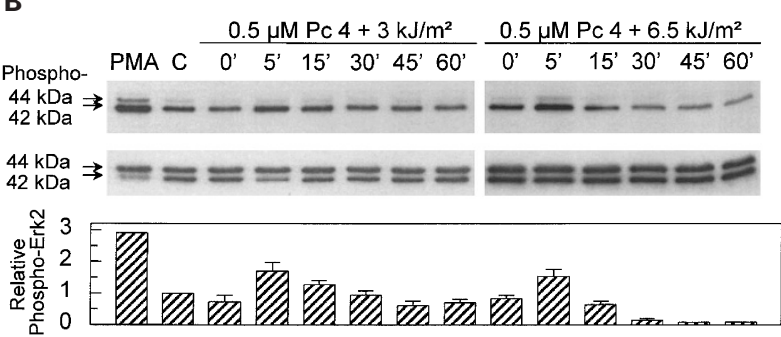

Figure 2 ERK phosphorylation in PDT-treated LY-R and CHO cells. Cells were untreated or treated with $0.5 \mu \mathrm{M} \mathrm{Pc} 4$ for $18 \mathrm{~h}$, then exposed to 2.1 or $3 \mathrm{~kJ} /$ $\mathrm{m}^{2}$ for LY-R cells (A) and 3 or $6.5 \mathrm{~kJ} / \mathrm{m}^{2}$ for $\mathrm{CHO}$ cells (B). Cells were collected at the indicated times post-PDT. Equal amounts of protein were loaded on minigels, electrophoresed and transferred to PVDF membranes and probed with a phospho-specific ERK1/ERK2 antibody (top panels) and a control ERK1/ERK2 antibody (lower panel of $\mathbf{A}$; middle panel of $\mathbf{B}$ ). The left lanes contained proteins from cells treated with $100 \mathrm{nM}$ PMA at $37^{\circ} \mathrm{C}$ for $20 \mathrm{~min}$. In (A), the apparent slight increase in intensity of the $42 \mathrm{kDa}$ band at $5 \mathrm{~min}$ postPDT was not reproduced in two other experiments. To quantify the results for $\mathrm{CHO}$ cells (B), the bands from this and two other independent experiments were scanned by densitometry. The ratio of densities of each phospho-ERK2 band (upper panel) and the corresponding non-phosphorylated ERK1 (middle panel) was calculated (see text), normalized to the control ratio, and the mean \pm standard deviation plotted (bottom panel of $\mathbf{B}$ )

bottom panel of Figure 2B presents the results for ERK2 activation, calculated as the ratio of the densities of the phosphorylated ERK2 band to that of the non-phosphorylated ERK1 band for each sample, normalized to the control, and averaged from three independent experiments. This analysis demonstrates that ERK2 phosphorylation in $\mathrm{CHO}$ cells increases about $50 \%$ over the baseline level by 5 min following either an LD90 or an LD99 dose of PDT and falls thereafter. For cells treated with the higher PDT dose, ERK2 phosphorylation decreased to about $10 \%$ of the untreated control 45 and 60 min after treatment.

The possible involvement of SAPK/JNK in PDT-induced apoptosis was investigated (Figure $3 A, B$ ) by Western blot analysis with antibodies recognizing the phosphorylated (Figure $3 A, B$, panels a) and total (Figure $3 A, B$ panels $b$ ) SAPK/JNK. For both LY-R and $\mathrm{CHO}$ cells, the panels $b$ of Figure $3 A, B$ indicate approximately equal loading of SAPK protein from each sample, whereas the panels a of Figure $3 A, B$ reveal a marked increase in the phosphorylation of both p54 and p46 SAPKs, beginning as early as 15 min post-PDT and continuing for at least $1 \mathrm{~h}$. For both cell lines, the data for this and two additional experiments were quantified by densitometric scanning of the bands. The data for LY-R cells (Figure $3 A$ ) were normalized to the untreated control cells. In contrast, because of the very low level of phosphorylated SAPK in control $\mathrm{CHO}$ cells, the 
A

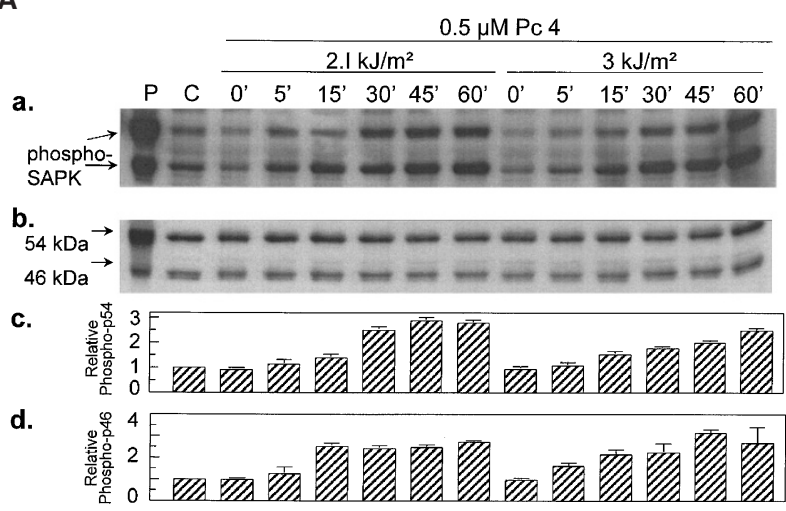

B

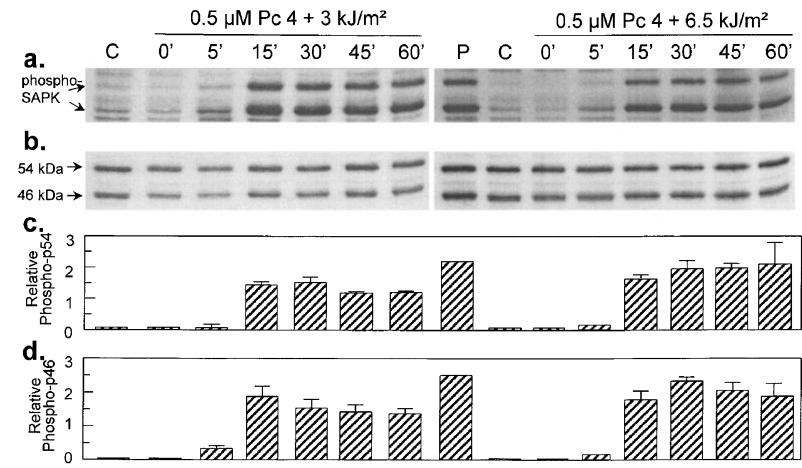

Figure 3 PDT-induced SAPK activation in LY-R and $\mathrm{CHO}$ cells. The same samples from control and PDT-treated LY-R and $\mathrm{CHO}$ cells as described in Figure 2 were separated on minigels, transferred to PVDF membranes, and probed with a phospho-specific anti-SAPK antibody (panel a) and a control anti-SAPK antibody (panel b). (A) SAPK activation in PDT-treated LY-R cells The left lane contains proteins from UVC-treated 293 cells as a positive control. (B) SAPK activation in PDT-treated $\mathrm{CHO}$ cells. The lanes marked P contain proteins from cells treated with anisomycin $(20 \mu \mathrm{g} / \mathrm{ml}$ for $30 \mathrm{~min})$. The positions of p54 and p46 SAPKs are indicated by arrows. Panels $c$ and $d$ represent the relative levels of phosphorylated p54 and p46, calculated as the ratio of the density in panel $\mathbf{a}$ to that in panel $\mathbf{b}$ for each sample and furthe normalized to the control (A) or not (B). Each datum in panels $\mathbf{c}$ and $\mathbf{d}$ is the mean \pm s.d. of results from three independent experiments

data presented in panels $c$ and $d$ of Figure $3 B$ were not normalized. As revealed in panels a, $c$ and $d$ of Figure $3 \mathrm{~A}$, the earliest response in PDT-treated LY-R cells was observed at $15 \mathrm{~min}$, and the activation continued for at least $1 \mathrm{~h}$. Similar time courses were observed for the LD90 and LD99 PDT doses. For $\mathrm{CHO}$ cells, a strong response was observed in PDT-treated $\mathrm{CHO}$ cells that reached a maximum level by $15 \mathrm{~min}$, and the high level of phosphorylation of both p54 and p46 persisted for at least $1 \mathrm{~h}$ (Figure 3B).

Figure 4 shows the effect of PDT on p38/HOG activation. In LY-R cells, the level of phosphorylated p38/ HOG was constitutively high, and PDT did not appear to increase it further over the first hour after either dose (Figure 4A). In contrast, little or no $338 / \mathrm{HOG}$ was found to be phosphorylated in untreated $\mathrm{CHO}$ cells (Figure 4B). However, PDT resulted in marked p38/HOG activation that was both time- and dose-dependent (Figure 4B). The
A

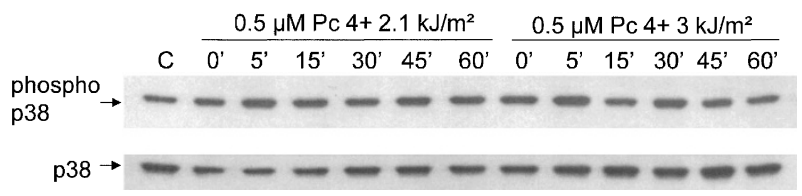

B
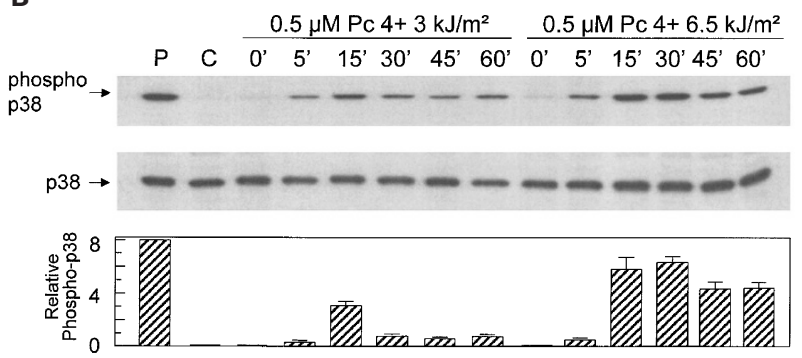

Figure 4 The response of $\mathrm{p} 38 / \mathrm{HOG}$ to PDT in LY-R cells $(\mathbf{A})$ and $\mathrm{CHO}$ cells (B) detected by a phospho-specific $\mathrm{P38} / \mathrm{HOG}$ antibody. The same samples described in Figure 2 were separated on minigels, transferred and blotted with a phospho-specific p38/HOG antibody (top panels) and a control anti-p38 antibody (bottom panel in $\mathbf{A}$; middle panel in $\mathbf{B}$ ), then detected by ECL. The left lane in B represents anisomycin-treated $(20 \mu \mathrm{g} / \mathrm{ml}$ for $30 \mathrm{~min})$ cells. In (A) the slightly greater intensity of the phospho-p38 band at $5 \mathrm{~min}$ post-PDT was not observed in two other experiments. In (B) the changes in phosphorylation were quantified by densitometry and calculated as the ratio of the densities of the phosphorylated p38 to that of non-phosphorylated p38. Each datum is the mean \pm s.d. of results obtained from three independent experiments

response began as early as $5 \mathrm{~min}$ after either PDT dose. The bottom panel of Figure 4B shows p38 activation calculated as the ratio of the densities of the phosphorylated p38 band to that of non-phosphorylated p38 for each sample. For the control sample, the ratio is nearly 0 . For the lower (LD90) PDT dose, a ratio of $\sim 3$ was achieved in $15 \mathrm{~min}$ after which the level declined. For the higher (LD99) PDT dose, the level of phosphorylated p38 reached a higher maximum (ratio of $\sim 6$ ), was maintained until $30 \mathrm{~min}$ post-PDT, and declined more slowly (bottom panel, Figure $4 B)$.

A characteristic feature of apoptosis is proteolytic cleavage of specific cellular proteins, including poly(ADPribose) polymerase (PARP), by one or more cysteinerequiring proteases, now termed caspases. ${ }^{34-36}$ Cleavage of PARP at the DEVD motif results in the generation of an Mr 90000 fragment from the Mr 116000 native enzyme. In order to better understand the involvement of MAPK family members in PDT-induced apoptosis, we measured PARP cleavage in cells treated with PDT in the presence or absence of an inhibitor of ERK or p38/HOG. Figure $5 \mathrm{~A}, \mathrm{~B}$ show the effects of SB202190, a specific inhibitor of p38/ $\mathrm{HOG}$, on the activation of $\mathrm{p38} / \mathrm{HOG}$ and on PARP cleavage in PDT-treated LY-R and $\mathrm{CHO}$ cells. In Figure 5A, DNA fragmentation was also determined. Preincubation with SB202190 for $30 \mathrm{~min}$ (LY-R) or $60 \mathrm{~min}$ (CHO) partially reduced the level of p38 phosphorylation below that of untreated control cells but did not induce PARP cleavage. When LY-R cells were treated with $0.5 \mu \mathrm{M} \mathrm{Pc} 4$ and $3 \mathrm{~kJ} /$ $\mathrm{m}^{2}$, the Mr 90000 PARP fragment was apparent by $30 \mathrm{~min}$ after PDT, and the cleavage of PARP was nearly complete 
A

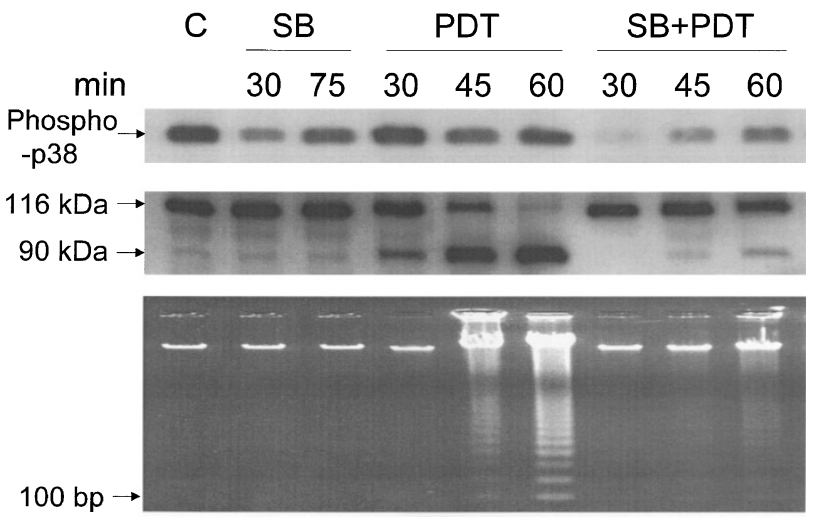

B

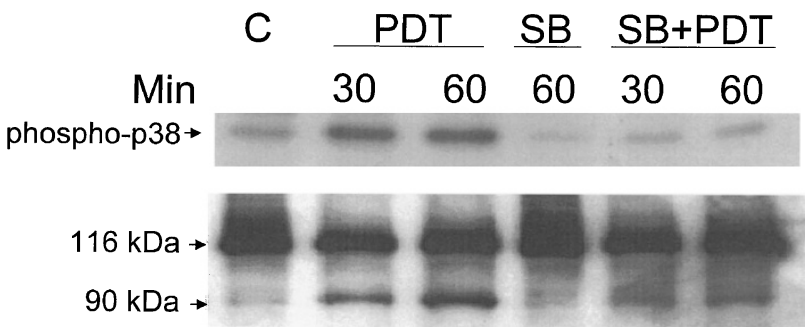

C

SB

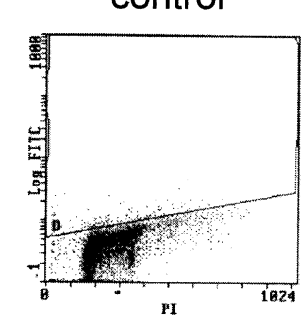

3.8

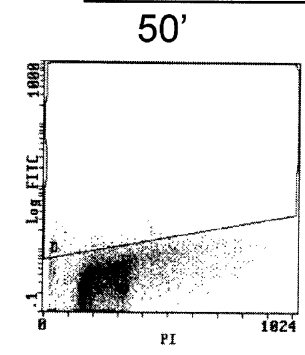

1.8

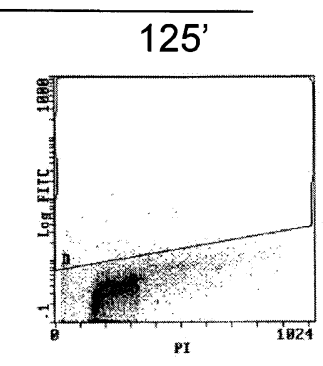

2.3
$\%$ Apoptotic cells

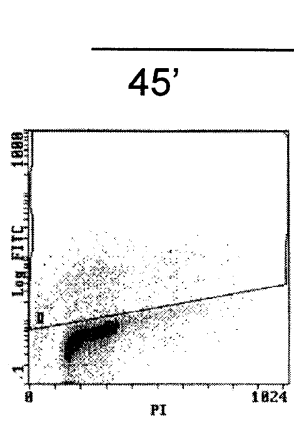

11.2
PDT

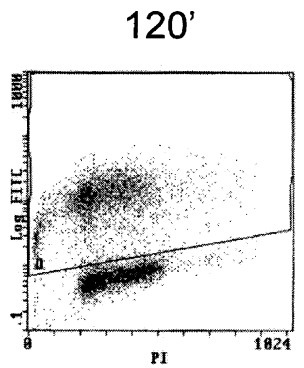

54.5

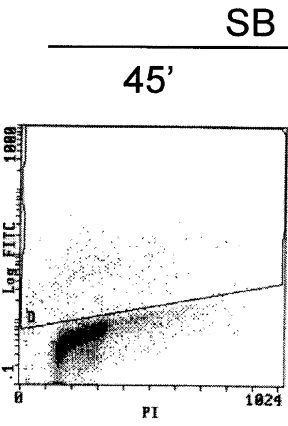

4.5
120 post-PDT

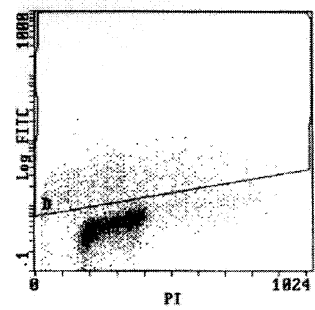

$16.2 \%$ Apoptotic cells

D

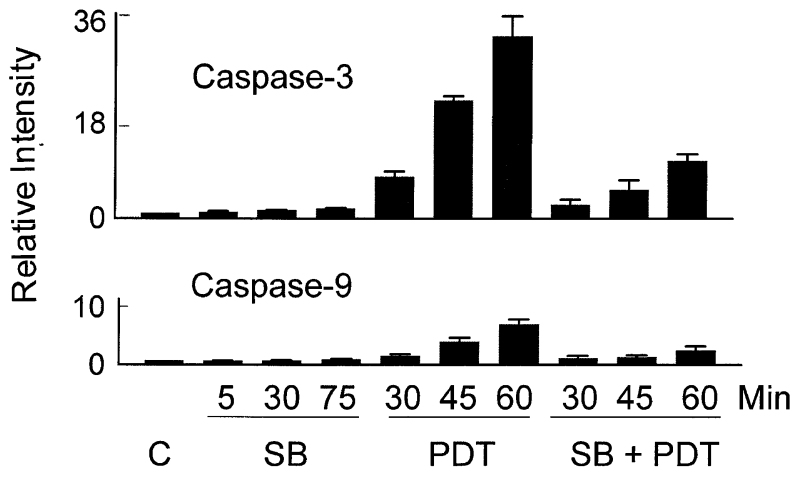

Figure 5 The effects of the p38/HOG inhibitor SB202190 (SB) on PDT-induced apoptosis and p38 activity in LY-R $(\mathbf{A}, \mathbf{C}, \mathbf{D})$ and $\mathrm{CHO}(\mathbf{B})$ cells. Cells were treated with $0.5 \mu \mathrm{M}$ Pc 4 for $18 \mathrm{~h}$, then incubated in $15 \mu \mathrm{M}$ SB202190 for $30 \mathrm{~min}(\mathbf{A}, \mathbf{B})$ or $5 \mathrm{~min}(\mathbf{C}, \mathbf{D})$ before irradiation. Cells were exposed to $3 \mathrm{~kJ} / \mathrm{m}^{2}$ for LY-R cells and $15 \mathrm{~kJ} / \mathrm{m}^{2}$ for $\mathrm{CHO}$ cells. The inhibitor remained in the cultures during and after irradiation. At various time points, cells were collected for DNA fragmentation assay (bottom panel of $\mathbf{A}$ ) and for Western blot analysis with the phospho-specific p38 antibody (top panel) and with the anti-PARP antibody (middle panel in $\mathbf{A}$ and bottom panel in B). Other samples were collected for assay of \% apoptotic (TUNEL-positive) cells by flow cytometry (C) or caspase-3 and caspase- 9 activity (D). The height of the bars in $\mathbf{D}$ represents the average of results from two independent experiments with the error bars indicating the range of values 
by $1 \mathrm{~h}$ at which time DNA fragmentation was extensive. PDT itself did not alter the level of p38/HOG activation, in agreement with the results in Figure 4A. However, when LY-R cells were preincubated in SB202190 for $30 \mathrm{~min}$ before red light irradiation, the level of $\mathrm{p} 38 / \mathrm{HOG}$ activation was reduced, and both PARP cleavage and DNA fragmentation were markedly inhibited (Figure 5A). In order to further define the effect of the p38 inhibitor on PDT-induced apoptosis, LY-R cells were treated with SB202190 and/or PDT and apoptosis was quantified by flow cytometry. As shown in Figure $5 \mathrm{C}$, incubation with SB202190 for 50 or $125 \mathrm{~min}$ did not induce apoptosis (Figure 5C, top panel). For PDT-treated cells, samples were collected at $45 \mathrm{~min}$ and $120 \mathrm{~min}$ post-PDT. Because the postincubation period up to $2 \mathrm{~h}$ was longer than in previous experiments (e.g. $1 \mathrm{~h}$ in Figure 5A), SB202190 was added to the culture $5 \mathrm{~min}$ rather than $30 \mathrm{~min}$ before irradiation. The bottom panels of Figure $5 \mathrm{C}$ indicate that preincubation in SB202190 for $5 \mathrm{~min}$ significantly reduced the induction of apoptosis by $60-70 \%$ in the $2 \mathrm{~h}$ post-PDT period. Figure 5D shows the effect of the p38 inhibitor on caspase-3 and caspase-9 activation in PDT-treated LY-R cells. It is clear that SB202190 markedly inhibited the activation of both caspases. In conclusion, although p38 activation was constitutively high and not affected by PDT in LY-R cells (Figures 4A and 5A), the results with the p38 inhibitor (Figure $5 \mathrm{~A}$ ) suggest that $\mathrm{p} 38$, in fact, is required for PDT-induced apoptosis.

The effects of SB202190 on p38 activity and PARP cleavage were also studied in PDT-treated $\mathrm{CHO}$ cells. As shown in Figure 5B, pretreatment with SB202190 partially

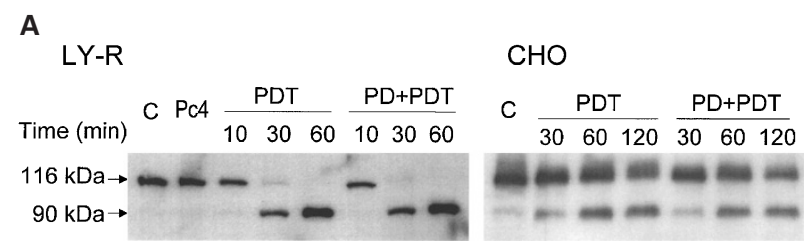

B

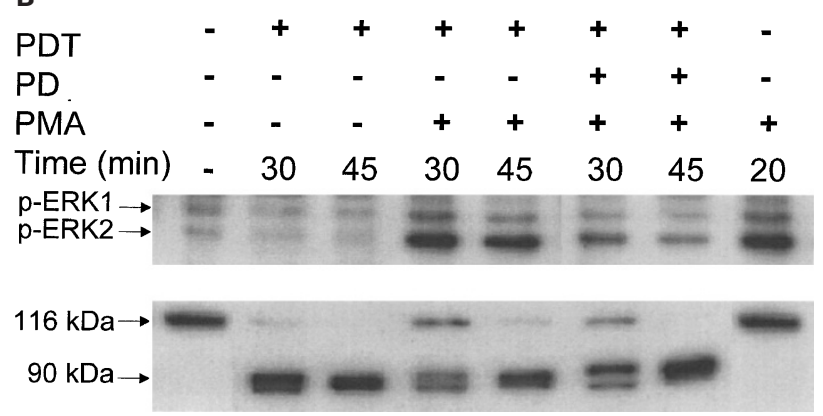

Figure 6 The effects of the MEK1 inhibitor PD98059 (PD) on PDT-induced PARP cleavage in LY-R (left panel, $\mathbf{A}$ ) and $\mathrm{CHO}$ (right panel, $\mathbf{A}$ ) cells and on both ERK activation and PARP cleavage in LY-R cells (B). Cells were treated with $0.5 \mu \mathrm{M}$ Pc 4 for $18 \mathrm{~h}$, then preincubated in $50 \mu \mathrm{M}$ PD98059 for $1 \mathrm{~h}$ before exposure to $3 \mathrm{~kJ} / \mathrm{m}^{2}$ (LY-R cells) or $15 \mathrm{~kJ} / \mathrm{m}^{2}$ (CHO cells). The inhibitor remained in the cultures until the cells were harvested. The samples were analyzed by Western blot with anti-PARP antibody (A) and both anti-PARP and anti phospho-specific antibodies (B). In (B) some cells were preincubated with $20 \mathrm{nM}$ PMA for $20 \mathrm{~min}$ alone or before irradiation to $3 \mathrm{~kJ} / \mathrm{m}^{2}$ inhibited both PDT-induced p38 activation and PARP cleavage, although both responses may recover at later times. The fact that PARP cleavage was at least partly reduced in cells in which p38 activity was inhibited implies that the p38/HOG pathway is involved in PDT-induced apoptosis in $\mathrm{CHO}$ cells.

A specific inhibitor of MEK1 (MAPK kinase) was also investigated in LY-R and $\mathrm{CHO}$ cells (Figure 6A). In the absence of PDT, PD98059 was found to have no effect on either ERK activation or PARP cleavage in either cell line (data not shown). Furthermore, we found no retardation of PARP cleavage when cells were preincubated with PD98059 for $1 \mathrm{~h}$ before red light irradiation. Because of these negative results and our earlier observations of little or no activation of ERKs by PDT, we questioned whether or not the inhibitor was active in our cells. Therefore, we took advantage of the strong activation of ERK1 and ERK2 by PMA in LY-R cells to test the effectiveness of PD98059 (Figure 6B). As observed previously (Figure 2A), PDT alone did not increase ERK activation. When LY-R cells were treated with PMA for $20 \mathrm{~min}$, there was a modest activation of ERK1 and a stronger response of ERK2. PDT did not further increase ERK activation in PMA preincubated cells, implying that ERK activation could be entirely attributed to PMA. In the presence of PD98059, the PMA-promoted ERK activation was partially inhibited. As shown in the bottom panel of Figure $6 \mathrm{~B}$, PARP was completely cleaved when cells were treated with PDT alone. For cells treated with PDT and PMA, ERKs were strongly activated, and PARP cleavage was slightly slowed. The further addition of PD98059, although partially inhibiting ERK activation, had little or no effect on PARP cleavage.

\section{Discussion}

In the present study, we have compared two cell lines with respect to their constitutive levels of phosphorylation of three MAPK family members, ERK1/ERK2, SAPK/JNK and p38/ $\mathrm{HOG}$, and the levels induced by lethal doses of PDT. For PDT-treated LY-R cells, although apoptosis occurs rapidly, and DNA fragmentation can be observed as early as 1020 min post-PDT, neither ERK1/ERK2 nor p38/HOG were activated by PDT. However, SAPK was activated in response to PDT in LY-R cells. In contrast, for $\mathrm{CHO}$ cells, that undergo a slower and less extensive apoptotic response, ERK2 phosphorylation was slightly elevated at $5 \mathrm{~min}$ post-PDT. Both SAPK and p38/HOG were activated by PDT in $\mathrm{CHO}$ cells, and the extent of the activation depended on PDT dose and post-treatment time.

Numerous studies ${ }^{12,13,15,16}$ have implicated SAPK as a mediator of apoptosis following various agents. The results in this study showed that SAPK activity was increased by PDT (LD90 and LD99 doses) in both LY-R and $\mathrm{CHO}$ cells, in spite of the differences in their rate and extent of apoptosis. PDT may directly activate one of the approximately ten isoforms of $\mathrm{SAPK}^{37}$ or interact with upstream regulators, such as SAPK kinase, p21activated kinase or the Ras-regulated small GTP-binding proteins. $^{38}$ Verheij et al ${ }^{15}$ provided evidence that 
oxidative stress-induced release of ceramide was an upstream signal activating SAPK and apoptosis. PDT causes the release of ceramide from both LY-R and $\mathrm{CHO}$ cells, as well as a variety of other cell types, with a time course and dose response consistent with such a role. ${ }^{9,39}$ Thus, although a selective chemical inhibitor of SAPK has not yet been found, indirect evidence suggests the involvement of this stress kinase in promoting PDT-induced apoptosis.

According to one hypothesis, ${ }^{11}$ a dynamic equilibrium between ERK1/ERK2 and SAPK/p38 determines whether cells survive or undergo programmed cell death. However, ERK1/ERK2 and SAPK/p38 may not always have opposing effects, and they could be activated either separately or simultaneously depending on the cell type and stimulus. ${ }^{40-42}$ Although the induction of apoptosis by PDT is fast and complete in LY-R cells, neither ERK1 nor ERK2 phosphorylation were affected by PDT. However, pretreatment with PMA slightly inhibited PDT-induced PARP cleavage, and this protective effect could be partially abolished by preincubation of cells with PD98059. Thus, activation of ERK1/ERK2 may be a negative regulator of PDT-induced apoptosis. For PDTtreated $\mathrm{CHO}$ cells, in which apoptosis was slower and less extensive, ERK2 phosphorylation was slightly enhanced by $5 \mathrm{~min}$ after PDT. It is possible that the induction of apoptosis in PDT-treated $\mathrm{CHO}$ cells may be delayed by the early activation of ERK2.

SB202190 is reported to be an inhibitor of p38 kinase activity. ${ }^{19,43}$ p38 activation requires phosphorylation on threonine-180 and tyrosine-182 by a dual specificity kinase, such as MKK3, MKK6, or JNKK1. ${ }^{4-46}$ Our results show that SB202190 also inhibits p38 phosphorylation. This secondary action is likely due to inhibition of the activating kinase (or activation of a p38 phosphatase). In addition, the inhibitory effect appears to be reversible with time.

In LY-R cells, SB202190 significantly inhibited PDTinduced PARP cleavage, DNA fragmentation, activation of caspases-3 and -9 , and appearance of apoptotic cells, suggesting that blockade of the p38 pathway is sufficient to prevent apoptosis. Although no p38 activation was observed after PDT-treatment in LY-R cells, inhibition of p38 by SB202190 is consistent with a role for p38 in PDTinduced apoptosis. In contrast, p38 was strongly activated in PDT-treated CHO cells and SB202190 markedly blocked p38 phosphorylation; however, the inhibitor had only a modest effect on PARP cleavage. One possible explanation for the observed difference in response of the two cell lines to SB202190 derives from differences in the constitutive levels of p38 phosphorylation. Thus, the high level of constitutively phosphorylated p38 in untreated control LY-R cells may contribute to the prompt induction of apoptosis in these cells by PDT, a response which is highly sensitive to depletion and inhibition of the phosphop38 pool. In contrast, $\mathrm{CHO}$ cells maintain their p38 in an unphosphorylated form and require several minutes to convert p38 to phospho-p38 following PDT. Possibly, the step in PDT-induced apoptosis that is promoted by phospho-p38 in LY-R cells is less dependent upon p38 activation in $\mathrm{CHO}$ cells. On the other hand, p38 may play a different role in apoptosis induced by various stimuli. Frasch et $\mathrm{al}^{17}$ found that anti-Fas induced or spontaneous apoptosis is independent of p38 activation and not blocked by the inhibitor. Roulston et $a f^{47}$ reported that SB203580 increased TNF $\alpha$-induced apoptosis. Nemoto et apo observed that SB202190 potentiated apoptosis induced by Fas ligand or UV irradiation. It appears that the involvement of p38 in apoptosis may be dependent on cell type, as well as stimulus. The function of $\mathrm{p} 38 / \mathrm{HOG}$ is complex and may trigger repair processes following cellular injury or initiate a program of cell death. ${ }^{48,49}$

There is now considerable evidence that PDT with several different photosensitizers activates the mitochondrial pathway of apoptosis. $\mathrm{We}^{30}$ and others ${ }^{28,29}$ have observed the rapid release of cytochrome $c$ from mitochondria and activation of caspases-9 and -3 with lesser activation of other caspases. It would thus appear that the cytochrome c/caspase-3 pathway may be sufficient to carry out apoptosis in PDT-treated cells. However, the results of the present study suggest that a product(s) of one or more of the MAPK cascades can modulate apoptosis, possibly by intersecting with the cytochrome c pathway.

Because activation of caspase-9, as well as caspase-3, was inhibited by SB202190, the primary step that is affected may be upstream of these caspases, perhaps at the level of formation of the Apaf-1:cytochrome c: dATP: procaspase-9 complex. Although we do not yet know what the MAPK pathway products might be that modulate PDT-induced apoptosis, the present data allow the development of hypotheses to be tested in further work. The p38 kinase is responsible for phosphorylating several transcription factors such as ATF-2, MAX, CHOP/ GADD153 and CREB ${ }^{50-52}$ that in turn lead to the elevated expression of a set of genes, including IL-6. ${ }^{53}$ The constitutively active p38 of LY-R cells may ensure the presence of a high steady-state level of a gene product(s) that promotes prompt entry into apoptosis upon damage from PDT. When p38 phosphorylation is inhibited by SB202190, the steady-state level of the essential, but unstable, gene product may decline rapidly, limiting the ability of PDT-damaged cells to undergo apoptosis.

A modified model may explain the results in $\mathrm{CHO}$ cells. In the case of $\mathrm{CHO}$ cells, there is little or no constitutively active p38 and thus a low level of the putative essential factor. The post-PDT time lag for p38 activation and synthesis of the essential factor may explain at least in part the lag in the entry of $\mathrm{CHO}$ cells into apoptosis. Furthermore, the modest inhibition of apoptosis (PARP cleavage) afforded by SB202190 may reflect the delayed generation of active p38 during the period the inhibitor is present or a very strong PDT-induced activation of p38 that may be less susceptible to inhibition. It is also possible that $\mathrm{CHO}$ cells have more of the $\beta$ isoform of $\mathrm{p} 38$ than do LY-R cells. It has been proposed ${ }^{20}$ that $\mathrm{p} 38 \beta$ is a suppressor whereas $p 38 \alpha$ is a mediator of apoptosis. Therefore, inhibition of $\mathrm{p} 38 \beta$ could actually increase cell susceptibility to apoptosis. It is also possible that the SAPK pathway, that is not inhibited by SB202190, contributes to PDT-induced apoptosis in $\mathrm{CHO}$ cells to a greater extent than in LY-R 
cells. Additional work will be required to elucidate the precise role of these signaling pathways in regulating PDTinduced apoptosis.

\section{Materials and Methods}

\section{Cell culture}

Mouse lymphoma L5178Y cells (strain LY-R) were grown in suspension culture in Fischer's medium containing $0.1 \%$ pluronic F68, 2 mM sodium pyruvate, and $10 \%$ heat-inactivated horse serum. ${ }^{4}$ Monolayer cultures of $\mathrm{CHO}$ cells (line 5A100) were originally obtained from Dr. D. Green, La Jolla Cancer Institute, and were maintained in McCoy's 5 A medium containing $10 \%$ fetal bovine serum and $20 \mathrm{mM} \mathrm{N}$ 2-hydroxyethylpiperazine $\mathrm{N}^{\prime}$-2-ethane-sulphonic acid ( $\left.\mathrm{pH} 7.4\right)$. The cultures were grown in a humidified atmosphere at $37^{\circ} \mathrm{C}$ with $5 \% \mathrm{CO}_{2}$.

\section{Photodynamic treatment}

The phthalocyanine photosensitizer $\mathrm{Pc} 4$, HOSiPcOSi$\left(\mathrm{CH}_{3}\right)_{2}\left(\mathrm{CH}_{2}\right)_{3} \mathrm{~N}\left(\mathrm{CH}_{3}\right)_{2},{ }^{54}$ was provided by Drs. Ying-syi $\mathrm{Li}$ and Malcolm E. Kenney, Case Western Reserve University Department of Chemistry. It was dissolved in dimethyl formamide to $0.5 \mathrm{mM}$. Cells were loaded with $\mathrm{Pc} 4$ by addition of an aliquot of the stock solution to the culture medium $\sim 18 \mathrm{~h}$ before irradiation. In preparation for irradiation of $\mathrm{CHO}$ cells, the dye-containing medium was removed and replaced with $3 \mathrm{ml}$ of Hank's balanced salt solution with $\mathrm{Ca}^{2+}$ and $\mathrm{Mg}^{2+}$. LY-R cells were irradiated in their Pc 4-containing conditioned medium. The light source was a $500 \mathrm{~W}$ tungsten-halogen lamp placed 29 inches below the surface of a glass exposure tray and filtered (600$\mathrm{nm}$ long-pass filter). All irradiations were performed at room temperature, and the temperature during irradiation did not exceed $34^{\circ} \mathrm{C}$.

\section{Flow cytometry}

Cell fixation and staining were performed based on the APODIRECT ${ }^{\text {(ix }}$ Kit (Phoenix Flow Systems, Inc.), ${ }^{55}$ as we have previously described. ${ }^{32}$ Analysis was carried out in the Flow Cytometry Facility of the Case Western Reserve University/Ireland Cancer Center. Fluorescence measurements were made on an EPICS ESP flow cytometer (Coulter Corp.), activating at $488 \mathrm{~nm}$ and monitoring fluorescence emission at $520 \mathrm{~nm}$ (Fluorescein) and $623 \mathrm{~nm}(\mathrm{PI})$. Data analysis was supported by version 4.0 of the instrument software.

\section{Western blot analysis}

For study of MAPKs, control and PDT-treated cells were lysed in SDS sample buffer $(62.5 \mathrm{mM}$ Tris- $\mathrm{HCl}, \mathrm{pH} 6.8,2 \% \mathrm{w} / \mathrm{v}$ SDS, $10 \%$ glycerol, $50 \mathrm{mM}$ dithiothreitol, $0.1 \% \mathrm{w} / \mathrm{v}$ bromphenol blue) and boiled for $5 \mathrm{~min}$. Equivalent amounts of protein were loaded onto an $8 \%$ polyacrylamide gel, subjected to electrophoresis, transferred to a PVDF membrane and incubated with phospho-specific p44/42 ERK, SAPK, or p38/HOG antibodies (New England BioLabs, Inc. Beverly, MA, USA). The immune complexes were detected by ECL system (Amersham, Arlington Heights, IL, USA). After probing with phospho-specific antibodies, the membrane was washed and reprobed with the corresponding control p44/42 ERK, SAPK (New England BioLabs, Inc., Beverly, MA, USA), or p38/HOG (UBI, Lake Placid, NY, USA) to check the loading and calculate the ratio of activated to non-activated kinases. For study of PARP cleavage, cells were lysed and sonicated in a solution containing $0.5 \%$ sodium deoxycholate, $0.2 \%$ SDS, $1 \%$ Triton X-100, $5 \mathrm{mM}$ EDTA, $10 \mu \mathrm{g} / \mathrm{ml}$ leupeptin, $10 \mu \mathrm{g} / \mathrm{ml}$ aprotinin, and $1 \mathrm{mM}$ phenylmethyl sulfonyl fluoride in phosphate-buffered saline. An equal volume of $2 \times$ SDS sample buffer ( $125 \mathrm{mM}$ Tris, $\mathrm{pH} 6.8,4 \%$ SDS, $10 \%$ mercaptoethanol, and $20 \%$ glycerol) was added to the cell lysate. Proteins were separated and transferred as described above and then probed with a monoclonal anti-PARP antibody (Trevigen, Gaithersburg, MD, USA) and detected by ECL.

\section{DNA fragmentation analysis}

Cells were collected at various times after PDT. DNA isolation and gel electrophoresis were performed as previously described. ${ }^{4}$ Briefly, cell pellets were resuspended in $500 \mu \mathrm{l}$ of a solution containing $1 \times \mathrm{SSC}$ and $10 \mathrm{mM}$ EDTA, then $1 \%$ sodium lauryl sarkosinate and $0.1 \mathrm{mg} / \mathrm{ml}$ proteinase $\mathrm{K}$ were added, and the mixture was incubated at $50^{\circ} \mathrm{C}$ for at least $2 \mathrm{~h}$. The DNA was precipitated by addition of 2 volumes of absolute ethanol, resuspended in $200 \mu \mathrm{lTE}$, and briefly treated with $1 \mathrm{mg} / \mathrm{ml}$ RNase before loading onto a $1.5 \%$ agarose gel. After electrophoresis, the gel was stained with $0.5 \mu \mathrm{g} / \mathrm{ml}$ ethidium bromide and photographed under UV light.

\section{Caspase activity}

Approximately $2 \times 10^{6}$ cells were collected by centrifugation, and the washed cell pellet was resuspended in $120 \mu$ l of lysis buffer $(10 \mathrm{mM}$ $\mathrm{KCl}, 1 \mathrm{mM}$ EDTA, $1 \mathrm{mM}$ EGTA, $1 \mathrm{mM}$ PMSF, $100 \mu \mathrm{M}$ pepstatin, $100 \mu \mathrm{M}$ leupeptin, $0.5 \%$ Triton $\mathrm{X}-100$ and $20 \mathrm{mM}$ HEPES, $\mathrm{pH} 7.5$ ), incubated on ice for $20 \mathrm{~min}$, then sonicated and stored at $-80^{\circ} \mathrm{C}$ until use. Aliquots containing $50 \mu \mathrm{g}$ protein were incubated with $100 \mu \mathrm{M}$ DEVD-AMC or LEHD-AFC (for assay of caspase-3 and caspase-9, respectively; BIOMOL Research Laboratory, Inc., Plymouth Meeting, $\mathrm{PA}$, USA) in $60 \mu \mathrm{l}$ of caspase reaction buffer (10\% sucrose, $0.1 \%$ CHAPS, 1 mM EGTA, 1 mM EDTA, 5 mM DTT, 1 mM PMSF, $100 \mu \mathrm{M}$ pepstatin, $100 \mu \mathrm{M}$ leupeptin, $25 \mathrm{mM}$ HEPES, $\mathrm{pH} 7.4$ ) at $37^{\circ} \mathrm{C}$ for $1 \mathrm{~h}$. The released fluorescent product was measured in a Perkin-Elmer LS50 fluorometer ( $\lambda_{\mathrm{ex}} 380 \mathrm{~nm}$ and $\lambda_{\mathrm{em}} 460 \mathrm{~nm}$ for caspase- 3 assay; $\lambda_{\mathrm{ex}} 400 \mathrm{~nm}$ and $\lambda_{\mathrm{em}} 505 \mathrm{~nm}$ for caspase- 9 assay).

\section{Acknowledgements}

This research was supported by PHS grants P01 CA48735 and P30 43703 from the National Cancer Institute.

\section{References}

1. Agarwal $R$, Athar M, Urban SA, Bickers DR and Mukhtar $H(1991)$ Involvement of singlet oxygen in chloroaluminum phthalocyanine tetrasulfonate-mediated photoenhancement of lipid peroxidation in rat epidermal microsomes. Cancer Lett. 56: $125-129$

2. Henderson BW and Dougherty TJ (1992) How does photodynamic therapy work? Photochem. Photobiol. 55: 145-157

3. Moan J and Berg K (1992) Photochemotherapy of cancer: experimental research. Photochem. Photobiol. 55: 931-948

4. Agarwal ML, Clay ME, Harvey EJ, Evans HH, Antunez ARand Oleinick NL (1991) Phododynamic therapy induces rapid cell death by apoptosis in L5178Y mouse lymphoma cells. Cancer Res. 51: 5993-5996

5. He XY, Sikes RA, Thomsen S, Chung LWK and Jacques SL (1994) Photodynamic therapy with Photofrin II induces programmed cell death in carcinoma cell lines. Photochem. Photobiol. 59: 468-473

6. Luo Y, Chang CK and Kessel D (1996) Rapid initiation of apoptosis by photodynamic therapy. Photochem. Photobiol. 63: 528-534 
7. Oleinick NL and Evans HH (1998) The photobiology of photodynamic therapy: Cellular targets and mechanisms. Radiat. Res. 150: S146-S156

8. Agarwal ML, Larkin HE, Zaidi SIA, Mukhtar H and Oleinick NL (1993) Phospholipase activation triggers apoptosis in photosensitized mouse lymphoma cells. Cancer Res. 53: 5897-5902

9. Separovic D, He J and Oleinick NL (1997) Ceramide generation in response to photodynamic treatment of L5178Y mouse lymphoma cells. Cancer Res. 57: $1717-1721$

10. Williams GT and Smith CA (1993) Molecular regulation of apoptosis: genetic control of cell death. Cell 74: 777-779

11. Xia Z, Dickens M, Raingeaud J, Davis RJ and Greenberg ME (1995) Opposing effects of ERK and JNK-p38MAP kinase on apoptosis. Science 270: 1326-1331

12. Chauhan D, Kharbanda S, Ogata A, Urashima M, Teoh G, Robertson M, Kufe DW and Anderson KC (1997) Interleukin-6 inhibits Fas-induced apoptosis and stress-activated protein kinase activation in multiple myeloma cells. Blood 89: $227-234$

13. Chen YR, Wang X, Templeton D, Davis RJ and Tan TH (1996) The role of c-Jun $\mathrm{N}$-terminal kinase (JNK) in apoptosis induced by ultraviolet $\mathrm{C}$ and $\gamma$ radiation. J. Biol. Chem. 271: 31929-31936

14. Pfeilschifter J and Huwiler A (1996) Nitric oxide stimulates stress-activated protein kinases in glomerular endothelial and mesangial cells. FEBS Lett. 396: $67-70$

15. Verheij M, Bose R, Lin XH, Yao B, Jarvis WD, Grant S, Birrer MJ, Szabo E, Zon LI, Kyriakis JM, Haimovitz-Friedman A, Fuks Z and Kolesnick RN (1996) Requirement for ceramide-initiated SAPK/JNK signalling in stress-induced apoptosis. Nature 380: $75-79$

16. Yu R, Shtil AA, Tan TH, Boninson IB and Kong AT (1996) Adriamycin activated c-jun N-terminal kinase in human leukemia cells: a relevance to apoptosis. Cancer Lett. 107: 73-81

17. Frasch SC, Nick JA, Fadok VA, Bratton DL, Worthen GS and Henson PM (1998) p38 mitogen-activated protein kinase-dependent and -independent intracellular signal transduction pathways leading to apoptosis in human neutrophils. J. Biol. Chem. 273: 8389-8397

18. Cuenda A, Rouse J, Doza YN, Meier R, Cohen P, Gallagher TF, Young PR and Lee JC (1995) SB 203580 is a specific inhibitor of a MAP kinase homologue which is stimulated by cellular stresses and interleukin-1. FEBS Lett. 364: 229-233

19. Lee JC, Laydon JT, McDonnell PC, GallagherTF, Kumar S, Green D, McNulty D, Blumentahal MJ, Heys JR, Landvatter SW, Strickler JE, McLaughlin MM, Siemens IR, Fisher SM, Livi GP, White JR, Adams JL and Young PR (1994) A protein kinase involved in the regulation of inflammatory cytokine biosynthesis. Nature 372: $739-746$

20. Nemoto S, Xiang J, Huang S and Lin A (1998) Induction of apoptosis by SB202190 through inhibition of p38beta mitogen-activated protein kinase. J. Biol. Chem. 273: 16415-16420

21. Graves JD, Draves KE, Craxton A, Krebs EG and Clark EA (1998) A comparison of signaling requirements for apoptosis of human $B$ lymphocytes induced by the B cell receptor and CD95/Fas. J. Immunol. 161: 168-174

22. Kawasaki H, Morooka T, Shimohama S, Kimura J, Hirano T, Gotoh Y and Nishida $E$ (1997) Activation and involvement of p38 mitogen-activated protein kinase in glutamate-induced apoptosis in rat cerebellar granule cells. J. Biol. Chem. 272: $18518-18521$

23. Kummer JL, Rao PK and Heidenreich KA (1997) Apoptosis induced by withdrawal of trophic factors is mediated by $\mathrm{p} 38$ mitogen-activated protein kinase. J. Biol. Chem. 272: 20490-20494

24. Schwenger P, Bellosta P, Vietor I, Basilico C, Skolnik EY and Vilcek J (1997) Sodium salicylate induces apoptosis via p38 mitgoen-activated protein kinase but inhibits tumor necrosis factor-induced c-Jun N-terminal kinase/stress-activated protein kinase activation. Proc. Natl. Acad. Sci. USA 94: $2869-2873$

25. Tao JS, Sanghera JS, Pelech SL,Wong G and Levy JG (1998) Stimulation of stress-activated protein kinase and p38 HOG1 kinase in murine keratinocytes following photodynamic therapy with benzoporphyrin derivative. J. Biol. Chem. 271: $27107-27115$

26. Klotz LO, Fritsch C, Briviba K, Tsacmacidis N, Schliess F and Sies H (1998) Activation of JNK and p38 but not ERK MAP kinases in human skin cells by 5aminolevulinate-photodynamic therapy. Cancer Res. 58: 4297-4300

27. Oleinick NL, He J, Xue LY and Separovic D (1998) Stress-activated signalling responses leading to apoptosis following photodynamic therapy. Proc. SPIE 3247: $82-88$
28. Granville DJ, Carthy CM, Jiang H, Shore GC, McManus BM and Hunt DWC (1998) Rapid cytochrome crelease, activation of caspases 3, 6, 7 and 8 followed by Bap31 cleavage in HeLa cells treated with photodynamic therapy. FEBS Lett. 437: $5-10$

29. Kessel D and Luo Y (1999) Photodynamic therapy: A mitochondrial inducer of apoptosis. Cell Death Differ. 6: 28-35

30. Varnes ME, Chiu SM, Xue LY and Oleinick NL (1999) Photodynamic therapyinduced apoptosis in lymphoma cells: translocation of cytochrome c causes inhibition of respiration as well as caspase activation. Biochem. Biophys. Res. Commun. 255: 673-679

31. Xue LY, Qiu Y, He J, Kung HJ and Oleinick NL (1999) Etk/Bmx, a PH-domaincontaining tyrosine kinase, protects prostate cancer cells from apoptosis induced by photodynamic therapy or thapsigargin. Oncogene 18: 3391-3398

32. He J, Agarwal ML, Larkin HE, Friedman LR, Xue LY and Oleinick NL (1996) The induction of partial resistance to photodynamic therapy by the protooncogene BCL-2. Photochem. Photobiol. 64: 845-852

33. Xue LY, He J and Oleinick NL (1997) Rapid tyrosine phosphorylation of HS1 in the response of mouse lymphoma L5178Y-R cells to photodynamic treatment sensitized by the phthalocyanine Pc 4. Photochem. Photobiol. 66: $105-113$

34. Kaufmann SH, Desnoyers S, Ottaviano Y, Davidson NE and Poierer GG (1993) Specific proteolytic cleavage of poly(ADP-ribose) polymerase: an early marker of chemotherapy-induced apoptosis. Cancer Res. 53: 3976-3985

35. Lazebnik YA, Kaufmann SH, Desnoyers S, Poirier GG and Earnshaw WE (1994) Cleavage of poly(ADP-ribose) polymerase by a proteinase with properties like ICE. Nature 371: $346-347$

36. Cohen GM (1997) Caspases: the executioners of apoptosis. Biochem. J. 326: $1-16$

37. Gupta S, Barrett T, Whitmarsh AJ, Cavanagh J, Sluss HK, Derijard B and Davis RJ (1996) Selective interaction of JNK protein kinase isoforms with transcription factors. EMBO J. 15: 2760-2770

38. Symons M (1996) Rho family GTPases: the cytoskeleton and beyond. Trends. Biochem. Sci. 21: 178-181

39. Separovic D, Mann KJ and Oleinick NL (1998) Association of ceramide accumulation with photodynamic treatment-induced cell death. Photochem. Photobiol. 68: 101-109

40. Cano E and Mahadevan LC (1995) Parallel signal processing among mammalian MAPKs. Biochem. Sci. 20: 117-122

41. Coso OA, Chiariello M, Yu J, Teramoto H, Crespo P, Xu N, Miki T and Gutkind JS (1995) The small GTP-binding proteins Rac1 and Cdc42 regulate the activity of the JNK/SAPK signaling pathway. Cell 81: 1137-1146

42. Salmeron A, Ahmad TB, Carlile GW, Pappin D, Narsimhan RP and Ley SC (1996) Activation of MEK-1 and SEK-1 by Tpl-2 protooncoprotein, a novel MAP kinase kinase kinase. EMBO J. 15: 817-826

43. Jiang Y, Chen C, Li Z, Guo W, Gegner JA, Lin S and Han J (1996) Characterization of the structure and function of a new mitogen-activated protein kinase (p38 $\beta$ ). J. Biol. Chem. 271: 17920-17926

44. Moriguchi T, Kuroyanagi N, Yamaguchi K, Gotoh Y, Irie K, Kano T, Shirakabe K, Muro Y, Shibuya H, Matsumoto K, Nishida E and Hagiwara M (1996) A novel kinase cascade mediated by mitogen-activated protein kinase kinase 6 and MKK3. J. Biol. Chem. 271: 13675-13679

45. Raingeaud J, Whitmarsh AJ, Barrett T, Derijard B and Davis RJ (1996) MKK3- and MKK6-regulated gene expression is mediated by the p38 mitogen-activated protein kinase signal transduction pathway. Mol. Cell. Biol. 16: 1247-1255

46. Lin A, Minden A, Martinetto H, Claret FX, Lange-Carter C, Mercurio F, Johnson GL and Karin M (1995) Identification of a dual specificity kinase that activates the Jun kinases and p38-Mpk2. Science 268: 286-290

47. Roulston A, Reinhard C, Amiri P and Williams LT (1998) Early activation of c-Jun $\mathrm{N}$-terminal kinase and p38 kinase regulate cell survival in response to tumor necrosis factor alpha. J. Biol. Chem. 273: 10232-10239

48. Graves JD, Draves KE, Craxton A, Saklatvala J, Krebs EG and Clark EA (1996) Involvement of stress-activated protein kinase and p38 mitogen-activated protein kinase in mlgM-induced apoptosis of human B lymphocytes. Proc. Natl. Acad. Sci. USA 93: 13814-13818

49. Ichijo H, Nishida E, Irie K, Ten DP, Saitoh M, Moriguchi T, Takagi M, Matsumoto K, Miyazono Kand Gotoh Y (1997) Induction of apoptosis by ASK1, a mammalian MAPKKK that activates SAPK/JNK and p38 signaling pathway. Science 275 : $90-94$ 
50. Gupta S, Campbell D, Derijard B and Davis RJ (1995) Transcription factor ATF2 regulation by the JNK signal transduction pathway. Science 267: 389-393

51. Zervos AS, Faccio L, Gatto JP, Kyriakis JM and Brent R (1995) Mxi2, a mitogenactivated protein kinase that recognizes and phosphorylates Max protein. Proc. Natl. Acad. Sci. USA 92: $10531-10534$

52. Wang XZ and Ron D (1996) Stress-induced phosphorylation and activation of the transcription factor CHOP (GADD153) by p38 MAP Kinase. Science 272: $1347-1349$

53. Miyazawa K, Mori A, Miyata H, Akahane M, Ajisawa $Y$ and Okudaira H (1998) Regulation of interleukin-1-beta-induced interleukin- 6 gene expression in human fibroblast-like synoviocytes by p38 mitogen-activated protein kinase. J Biol. Chem. 273: 24832-24838
54. Oleinick NL, Antunez AR, Clay ME, Rihter BD and Kenney ME (1993) New phthalocyanine photosensitizers for photodynamic therapy. Photochem. Photobiol. 57: 242-247

55. Li X, Traganos F, Melamed MR and Darzynkiewicz Z (1995) Single step procedure for labeling DNA stand breaks with fluorescein- or BODIPYconjugated deoxynucleotides: Detection of apoptosis and bromodeoxyuridine incorporation. Cytometry 20: 172-180 